\section{Salinas insulares. Sal en Canarias en el Antiguo Régimen}

\section{Juan Manuel Santana-Pérez [*]}

\author{
[*] Catedrático de História Moderna, Universidad \\ de Las Palmas de Gran Canaria (ULPGC), Las \\ Palmas, Espanha. \\ juanmanuel.santana@ulpgc.es
}

ORCID: http://orcid.org/0000-0002-9505-9288
Resumen: Analizamos el papel de la sal en las Islas del Atlántico medio, en este ejemplo el caso de Canarias, donde contaba con elementos favorables para la producción: sol, viento, poca lluvia y un inmenso océano que la rodea, sin embargo, necesitaba importar sal. El periodo cronológico que estudiamos es el Antiguo Régimen (siglos XVI-XVIII). En esas centurias se fabricaron salinas en el archipiélago mayormente destinadas a la conservación de alimento, sobre todo, de pescados que eran capturados en el banco pesquero canario-sahariano. Indagamos la comercialización del producto, los contactos con la Corona portuguesa, por la estrecha relación que tuvo en este tiempo con las otras islas de la Macaronesia, Azores, Madeira y Cabo Verde y, también nos interesamos por conocer los proyectos ilustrados, que como en muchos otros terrenos, terminaron en fracaso o nunca llegaron a hacerse.

Palabras clave: Sal; Islas; Antiguo Régimen.

\section{Salinas insulares. Sal das Canárias no Antigo Regime}

Resumo: $\mathrm{O}$ artigo analisa o papel do sal nas ilhas do médio Atlântico, em especial nas Canárias, e procura esclarecer por que ilhas com sol, vento, cercadas pelo oceano, com pouca chuva, precisavam importar sal. Expõe a importância do sal no Antigo Regime, muito superior à atual. Analisa as salinas criadas nesse arquipélago, ligadas em grande medida à conservação de alimentos, principalmente peixes, em um terreno localizado no meio do banco de pesca do Saara; as dificuldades na comercialização do produto; os contatos com a Coroa portuguesa, com a qual mantinham forte relação durante os séculos XVI, XVII e XVIII, especialmente as ilhas da Macaronésia (Açores, Madeira e Cabo Verde), e, finalmente, examina os projetos ilustrados, que, como muitos outros, terminaram em fracasso ou nunca foram implementados.

Palaras-chave: Sal; Ilhas; Antigo Regime. 


\section{La sal en la sociedad del Antiguo Régimen}

L

a sal en el Antiguo Régimen fue un producto empleado en la industria y con uso doméstico, no sólo relacionado con el consumo directo en forma de sazonador de alimentos - donde se emplea la de mayor calidad - sino, fundamentalmente, como elemento indispensable en la preservación de diversos productos, carnes y pescados. De hecho, sabemos que en Canarias era prácticamente el único medio para conservarlos, incluso aquí hubo mayor dependencia de sal si tenemos en cuenta que no alcanzan bajas temperaturas en ninguna época del año. Además, el archipiélago canario tiene 1.583 kilómetros de costa, a menos de cien kilómetros al continente africano y queda enmarcado en el Banco Sahariano, uno de los más ricos del mundo, conocido desde la Antigüedad por diversos pueblos, lo que llevó a que la pesca fuese una actividad de gran importancia (Santana e Santana, 2014).

También se empleó sal en otros cometidos, como la elaboración de quesos, mezclada con la comida del ganado, y en el curtido de pieles. En ésta última, se empleaba la sal de peor calidad, la más ennegrecida por estar mezclada con la tierra. Incluso, se le confería poderes mágicos y era utilizada en ciertos ritos de hechicería. También servía para blanquear vidrios y dar una especie de vidriado a la loza, el ilustrado isleño Viera y Clavijo dice que tiene empleos medicinales, como estimulante y purgante, y según él contribuye a la digestión (Viera, 2005, p. 559).

Históricamente la sal ha sido considerada como un producto de gran valor. De ahí la evolución de la palabra salarium, remuneración de los soldados romanos que se realizaba en sal, origen del actual vocablo "salario". Igualmente, en la Edad Media y en la Edad Moderna, fue un producto altamente considerado. Contamos con un tratado publicado en 1579 que da muestra de ello, donde aborda el monopolio real, el comercio y tributos de la sal, además de una amplia reflexión acerca de sus diversos valores (Gómez, 2003).

La demanda era general a todas las personas. Era uno de los productos de abastecimiento imprescindibles, F. Braudel (1974, p. 160) escribió que en el Antiguo Régimen el consumo de sal podía llegar hasta los veinte gramos por día, el doble de la actual, debido a que, a pesar de las especias, continuaba siendo el elemento fundamental para dar sabor a las comidas, además de ser un conservante eficaz, es decir, que su importancia era ostensiblemente superior a la actualidad.

La sal se relaciona con el excedente que podía generarse y con la necesidad de mantener el pescado o la carne, entra en juego la necesidad de no inundar el mercado en un momento puntual y de este modo poder ir dosificando la llegada al mercado de la producción.

En los Reinos de España hubo distintos tipos de salinas. Unas eran salinas de piedra, como las de Castellar y Remolinos en Aragón, Cardona en Cataluña, Minglanilla en Cuenca y Villarrubia en La Mancha. Otras eran salinas marinas, como las de la Bahía de Cádiz, los 
Alfaques de Tortosa o Ibiza, mientras otras eran salinas de lagunas como La Mata, Orihuela y El Pinatar, en las que la sal cuajaba espontáneamente. También se obtenía sal de fuentes, pozos y manantiales salados de los que se sacaba la muera por medio de norias y otros artificios como ocurría en Lens en Guipúzcoa o Cabezón en Cantabria (Porres, 2003, p. 39).

La llegada ibérica a América y el cierre de mercados en Portugal para los holandeses a finales del siglo XVI, relanzó la producción de algunas salinas en ese continente como las de Araya (en la actual Venezuela) (Van den Boogaart et al., 1992, p. 91, 108, 109; Herrero, 1993, p. 173-194).

Toda la sal producida en Canarias procedía de salinas marinas. Se ha dicho que la sal es la riqueza de casi todos los mares, hasta el punto de que ha sido denominada "oro blanco", por oposición y comparación con el "oro negro" de los siglos XX y XXI que es el petróleo. El comercio de sal por mar llegó a ser el segundo renglón de la producción que más volumen movió, tras los cereales, al menos en los siglos XVII y XVIII, y España era una gran productora y exportadora de este artículo (Mollat du Jourdain, 1993, p. 146). En el Antiguo Régimen la producción de sal común por ebullición y refinado de sal de mar o de salina era un productivo negocio, explotado en competencia con el de la sal de producción doméstica (Kellenbenz, 1987, p. 175).

El mar, el sol y el viento eran las materias primas que en las islas del Atlántico medio favorecían las producciones salineras, además, la escasez de lluvia mejoraba su producción porque no se inundaban los cocederos. Desde antes del siglo XV, en Canarias, la sal era obtenida por las poblaciones aborígenes por medio de cocederos naturales, que consistían en el aprovechamiento de charcos en la orilla del mar para, una vez evaporada el agua, obtener el producto que los salineros llaman "sal de espuma" y dicen que es la de mejor calidad.

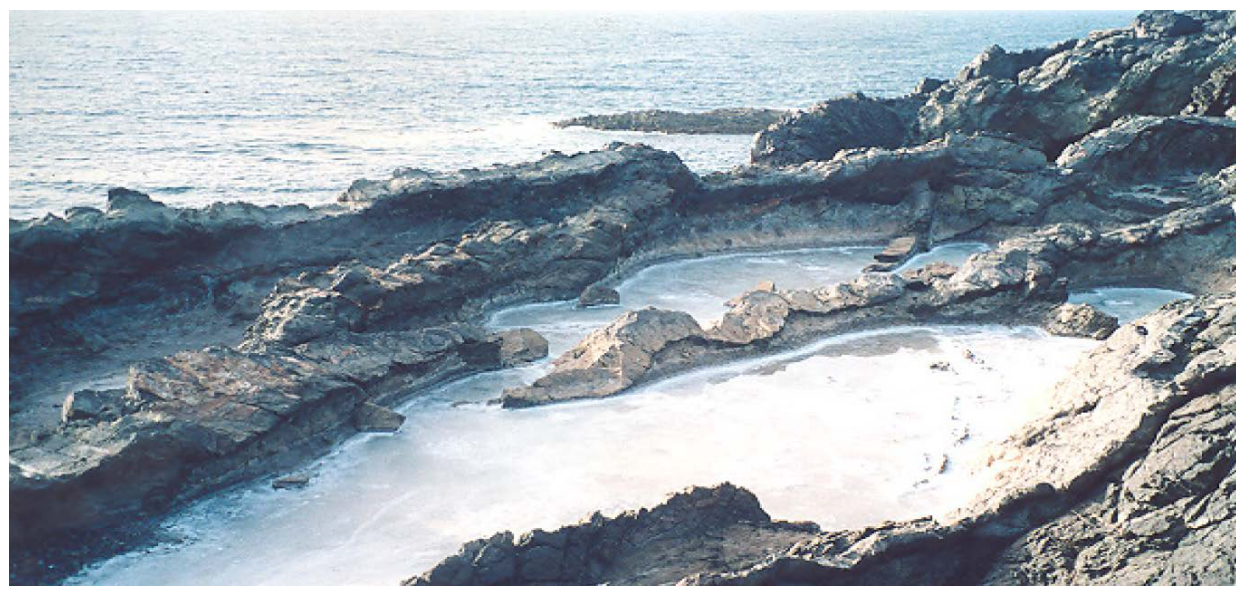

Figura 1: Cocedero natural en Fuerteventura (Fuente: Foto del autor). 
Esos mismos cocederos serán utilizados con posterioridad a la llegada masiva de los europeos. A esto se unió, poco tiempo después, la construcción de salinas, esto es, recintos rellenos de agua salada, con varios compartimentos comunicados. Al agua del mar que se introduce en el cocedero madre se le denomina agua fresca y la que está pasada de graduación y que es necesario eliminar porque no cristaliza es el agua caldea.

Desde los cocederos, el salinero lleva el agua a los tajos a través de un sistema de riego por medio de acequias y caños (en Tenerife llamado tajea). Primero hay un depósito mayor que sirve para acumular el agua que entra por el tomadero, ahí se deposita la tierra y otras impurezas, va pasando a estanques más pequeños donde va abandonando el carbonato cálcico (que denominan pecas) y el sulfato de calcio, hasta llegar a la última terraza donde deposita el cloruro sódico. El cocedero (soleadero o calentador en Tenerife) es el elemento principal consistente en grandes balsas de cuarenta o cincuenta centímetros de profundidad, donde el agua alcanza concentraciones de cuatro a 12 grados, antes de pasar a los tajos. Cuentan con una compuerta de madera que corre sobre dos guías laterales, que se emplea para regular el acceso del agua desde el sistema de captación hasta el cocedero. Las acequias primarias solían tener el suelo y las paredes revestidas de piedra.

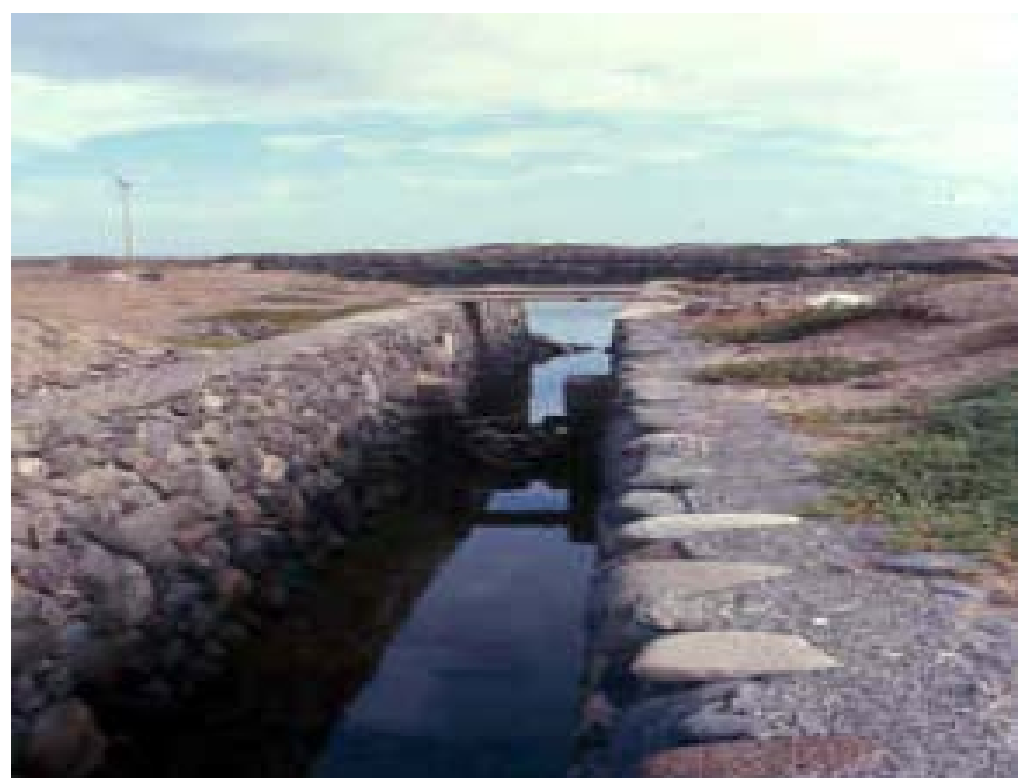

Figura 2: Tomadero de salinas de Tenefé, Gran Canaria (Fuente: Foto del autor).

La sal tarda en cristalizar entre tres y ocho días, es decir, cuando el agua alcanza un determinado grado de concentración de sal, que deja una fina capa en la superficie cuando llega a 25 grados, luego se pica y se saca del tajo. La zafra o cosecha se suele realizar de mayo 
a octubre, por ser la época de menos lluvia y de más insolación y viento, aunque se podía extender a los meses de invierno si escaseaban las lluvias. Una vez que ha alcanzado la temperatura adecuada gracias a la acción del sol y el viento, el salinero puede recoger la sal, este proceso tarda entre quince días y un mes, realizar ese conjunto de actividades se llama labrar, que se hace con la azada o azadón. La sal era extraída del tajo con un rastrillo que era de madera, aunque hoy en día es metálica. En Lanzarote se le denominaba raspillo y en Gran Canaria rodabillo.

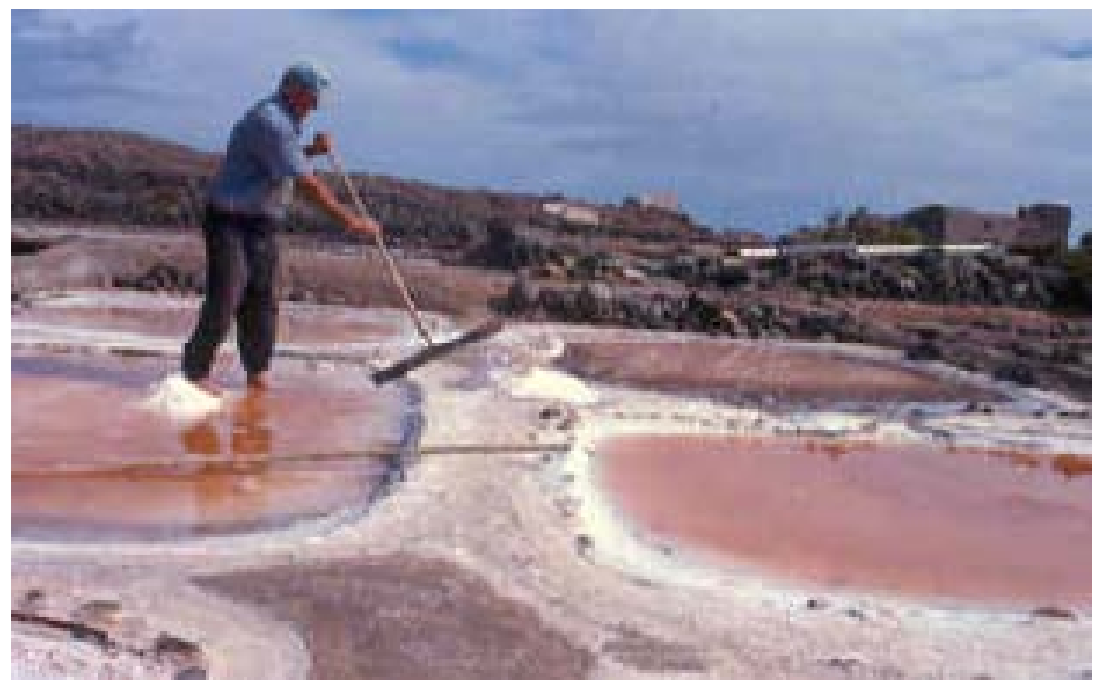

Figura 3: Labores de recogida de sal en Tenefé, Gran Canaria (Fuente: Foto del autor).

Una vez retirada de los tajos, la sal permanecía amontonada durante aproximadamente una semana en los balaches (los pasillos de tierra en medio de los tajos), y una vez seca, era trasladada al almacén. Cada tajo podía producir entre cuarenta y cincuenta kilogramos de sal, y cada día podían almacenarse entre doscientos y cuatrocientos kilogramos.

Es preciso hacer labores de mantenimiento anuales. Es necesario embarrar o extender los fondos de cocederos y tajos, además, apisonar, compactar el barro de los fondos para hacerlos impermeables, con pisón o rodillo, llamado rocín, de forma cilíndrica, que en el periodo que tratamos era de piedra. Además, cada cuatro o cinco años hay que limpiar los tajos que se van colmando de tierra, arreglando los fondos y el borde, lo que se denomina ensalonarlo.

El número de personas que trabajaban temporalmente en las salinas canarias podía llegar a ser considerable. Diariamente había que batir la sal o la nata, es decir, precipitar la capa cristalizada que se iba formando en la superficie del tajo, para acelerar el proceso y obtener sal más fina, normalmente se hacía a primera hora de la mañana y de la tarde. Si 
bien la administración y cuidado de la salina requería poca mano de obra, en determinadas épocas los labradores podían convertirse en trabajadores de la sal. En 1635, entre las cuentas que se toman a Manuel de Acuña, alcalde del valle de Haría, administrador de las salinas de Lanzarote, se le reciben por el descargo, entre otros capítulos, 483 reales por el valor de 184 hombres que trabajaban en dichas salinas, a razón de un tostón por cada hombre. ${ }^{1}$ Quien dirigía las operaciones de las salinas y tenía a cargo todo el personal era el capataz, le seguía un jefe de cuadrilla, el sota, que sustituía al capataz en su ausencia. El montonero era quien iba apilando con habilidad la montaña de sal, mientras que los trabajadores no especializados se llamaban peones. El cabatajo era el principiante de compañero e integrante de la cuadrilla que trabajaba el tajo en las labores más ingratas. También había un cargador para meter el producto en los burros, en las carretillas o en las vagonetas de sal. De cualquier modo, todos recibían el nombre genérico de salineros.

La mayoría de las salinas eran de propiedad realenga o señorial y su aprovechamiento estuvo regulado por los Concejos. La Corona hizo intentos por entregar en monopolio la producción y comercialización de sal, pero no se consiguió.

En Canarias siempre ha existido un activo tráfico insular de sal, muy difícil de seguir a través de los documentos. Este iba desde la costa hasta el interior donde se intercambiaba, casi siempre en forma de trueque, por otros artículos como cereales. Los intercambios protagonizados por arrieros tuvieron continuidad en el tiempo, gozando de gran regularidad entre las zonas costeras y el interior (González, 1996, p. 186-192). También suponemos que parte de la población costera se abastecía de sal, gracias a los cocederos y pequeños charcos que jalonaban la costa.

Las leyes del Reino español serán estrictas con aquéllos que produzcan o introduzcan sal sin las licencias pertinentes. Sin embargo, en Canarias, la regalía de la sal en un primer momento no fue ejercida en el plano fiscal. Su recogida y comercialización fue una actividad libre de toda intervención regia en el siglo XVI. Incluso los propios señores otorgaron facultad para abrir nuevas salinas en sus dominios. Pero a partir del año 1605 la creación de nuevas salinas exigió contar con la preceptiva autorización de la Corona, por la que recibía determinados derechos. ${ }^{2}$

Normalmente la sal se medía en fanegas y cahíces. Cada cahíz equivalía a 12 fanegas. ${ }^{3}$

'Archivo Histórico Provincial de Las Palmas (AHPLP). Escribano Tomás de Ganzo, Juan, leg. 2.733, año 1635, Lanzarote, fol. 238 V. ${ }^{2}$ Novísima recopilación de las leyes de España. Libro IX, Título XIX, Ley II. Edición Facsímil. Madrid, Boletín Oficial del Estado, 1975. También tenemos un extenso estudio en que se afirma lo mismo (Macías, 1989, p. 154) sobre la sal y, además, señala algunas claves para conocer su evolución.

${ }^{3}$ AHPLP. Escribano Tomás de Ganzo, Juan, leg. 2.732, año 1632, Lanzarote, fols. 459 r-460 r. En junio de 1632, se tenían que cargar doscientas fanegas de sal en Lanzarote que hacían 16 cahíces y ocho fanegas. 
Debemos comentar también que en 1501 los Reyes Católicos impusieron que Gran Canaria pagase de arancel de haber del peso para los propios, un maravedí por arroba de sal. ${ }^{4}$

Las entregas de sales para su utilización era una operación compleja que se desarrollaba en varias etapas. En primer lugar, era conveniente para emprender el transporte de la sal hasta la zona de embarque evitar las épocas de lluvias porque empapaban los caminos de las salinas. Aunque las salinas fueron bien concebidas, los estanques salineros no estaban bordeados por un canal accesible a las embarcaciones. Generalmente la conducción de sal era llevada por medio de animales de tiro. Las ruedas de las carretas cargadas con mucho peso abrirían surcos en los estrechos caminos que quedarían en muy mal estado con las primeras lluvias (Hocquet, 1988, p. 9). ${ }^{5}$ Generalmente un chico que se iniciaba en las tareas salineras, denominado hormiguilla, era el encargado de conducir los burros hasta los embarcaderos, que solían ser muelles de piedra de pequeñas dimensiones utilizados para embarcar sal y otros productos.

\section{Salinas}

En Canarias existían importantes salinas que, a diferencia de las más destacadas de la Península, no estaban sujetas a rentas reales. Más bien la obtención del producto y su comercialización fue una actividad ejercida libremente. La Corona se limitó a conceder permiso para la creación de nuevas salinas a partir de 1606, exigiendo, además de las tercias reales, el 7\% por su extracción (almojarifazgo) (Macías, 1989, p. 151-215).

Durante el Antiguo Régimen las principales salinas canarias se localizaron en las islas de Gran Canaria y Lanzarote. Pero, hasta hoy nos han llegado diversos topónimos en casi todas las islas, salvo en Tenerife, relacionados con esta producción: en La Palma: Roques de la Sal y Punta Salinas; en El Hierro: Punta de la Sal y Roque de la Sal; en La Gomera: Las Puntas de las Salinas; en Lanzarote: Salinas del Río; en Fuerteventura: Las Salinas, Caleta Salinas; en Gran Canaria: Punta Salinas, Punta de la Sal, La Salinilla, Salinetas, y Punta Salineta.

De las antiguas salinas se han conservado sólo cinco en Gran Canarias: la del Bufadero, la de la Florida, la de Playa de Vargas, la de Arinaga y la de Tenefé. Estas dos últimas han sido declaradas Bien de Interés Cultural.

${ }^{4}$ Libro Rojo de Gran Canaria o Gran Libro de Provisiones y Reales Cédulas, es una compilación de la fuente original del antiguo Cabildo de Gran Canaria, lo único que se salvó de un incendio (Cúllen, 1947, p. 145-149.

${ }^{5}$ Esto ha sido explicado para las salinas francesas del Mediterráneo y del Atlántico, pero ocurría lo mismo en Canarias y en el resto de España (Hocquet, 1988, p. 9). Se trata de un perfecto estudio sobre el trabajo en las salinas y sus infraestructuras. 


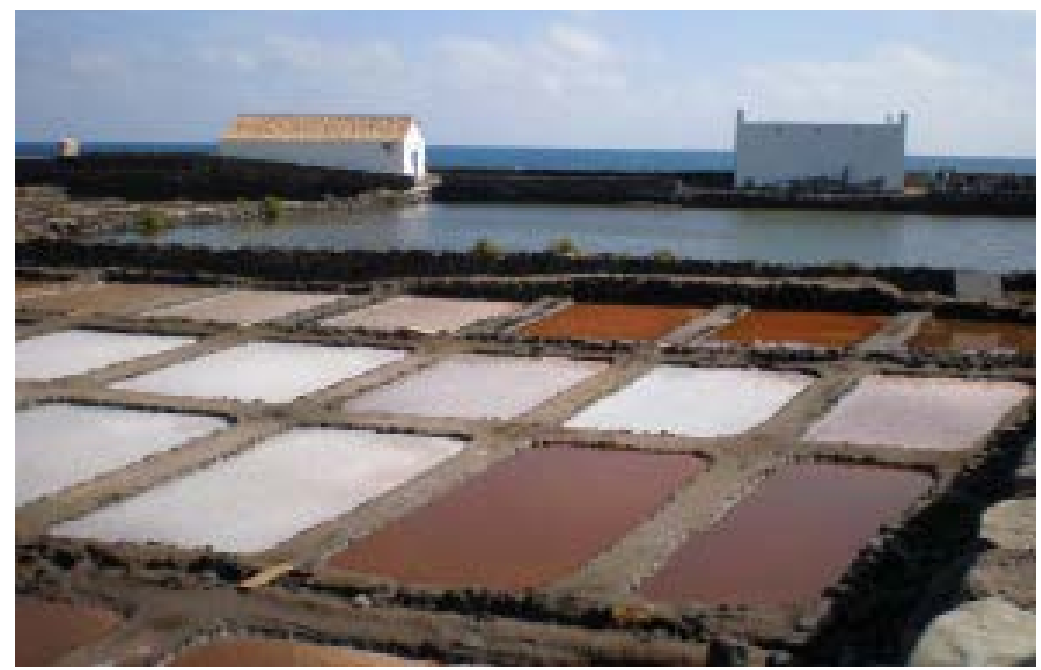

Figura 4: Salinas de Arinaga (Fuente: Foto del autor).

En alguna publicación referida a las salinas españolas aparecen las canarias pero se afirma erróneamente que comenzaron su explotación en el siglo XIX (Puche, Ayarzagüena, Mazadiego, 2009, p. 112), sin embargo, tenemos multitud de datos que prueban que hay que retrotraerlas a las centurias anteriores.

Fueron construidas salinas en el norte y en el este de Gran Canaria fundamentadas en respuesta a las necesidades de conservación del pescado extraído de las aguas norteafricanas; aún se conservan algunas pese al paso de los años.

Durante el siglo XVII hubo varias salinas entre las que sobresalen las de la costa aruquense, las de Agaete, las de Guanarteme en la zona del Rincón, en la desembocadura del Barranco de San Lorenzo, las salinas de Maspalomas, las de Aldea Blanca y las de las playas próximas a Agüimes ${ }^{6}$ en el sur. En 1673 se concedió un permiso al capitán don Antonio Lorenzo de Betancourt, quien más tarde, en 1696, hizo vínculo del castillo y las salinas a favor de su hijo don José Jacinto Betancourt Ayala y Rojas. ${ }^{7}$ Con todo, la más antigua de todas era la de Bañaderos.

Otras salinas que se construyeron en el siglo XVIII eran las llamadas del Bufadero (1721), en Arucas; las de Boca Cangrejo (a mediados del siglo XVIII), al norte de Playa de Vargas en el Carrizal de Agüimes; las anexas de la Florida (1820); las de Arinaga (a principios del

${ }^{6}$ Archivo de Acialcázar (AA). Invasiones. s/fol. En 1627 unos moros apresaron a Diego Suárez, alguacil de Agüimes, en unas salinas, a tres leguas de esa villa.

${ }^{7}$ AA. Lorenzo, S/fol. Este personaje, Antonio Lorenzo de Betancourt, llegó a Sargento Mayor y Regidor Perpetuo de Gran Canaria y en 1677 obtiene de Carlos II el título de Alcalde y Señor del Castillo de su Casa Fuerte del Romeral. 
siglo XIX, la primera referencia es la concesión que le hace el obispo Verdugo al abogado de los Reales Consejos Santiago Verdugo da Pelo (fechada el 27 de abril de 1804); las de Tenefé al sur de Pozo Izquierdo (1750), en Santa Lucía de Tirajana; las de Playa del Matorral en San Bartolomé de Tirajana; las cercanas de Las Casillas y la Caleta, todas ellas de principios del siglo XIX. Del siglo XVII contamos con las salinas de Juan Grande y las del Castillo del Romeral, en el mismo término municipal de San Bartolomé de Tirajana, además, de otras salinas citadas por el ilustrado canario Viera y Clavijo (Santana, 2017), quien señala: "Hay buenas salinas, cuya sal se consume principalmente en la pesca de Berbería", también cita entre las fortificaciones de Gran Canaria el "Castillo de Santa Cruz del Romeral en Las Salinas” (Viera, 1982, p. 398). Viera y Clavijo también señala que entre los pagos de Guía hay uno que también se llama Las Salinas, topónimo que podría indicar la existencia en otra época de algunas de ellas. Pero lo cierto es que actualmente no hay restos de su existencia, de hecho, dicho topónimo aparece en más lugares y creemos que más bien puede asociarse a lugares en que la gente aprovechaba charcos para aprovisionarse de sal.

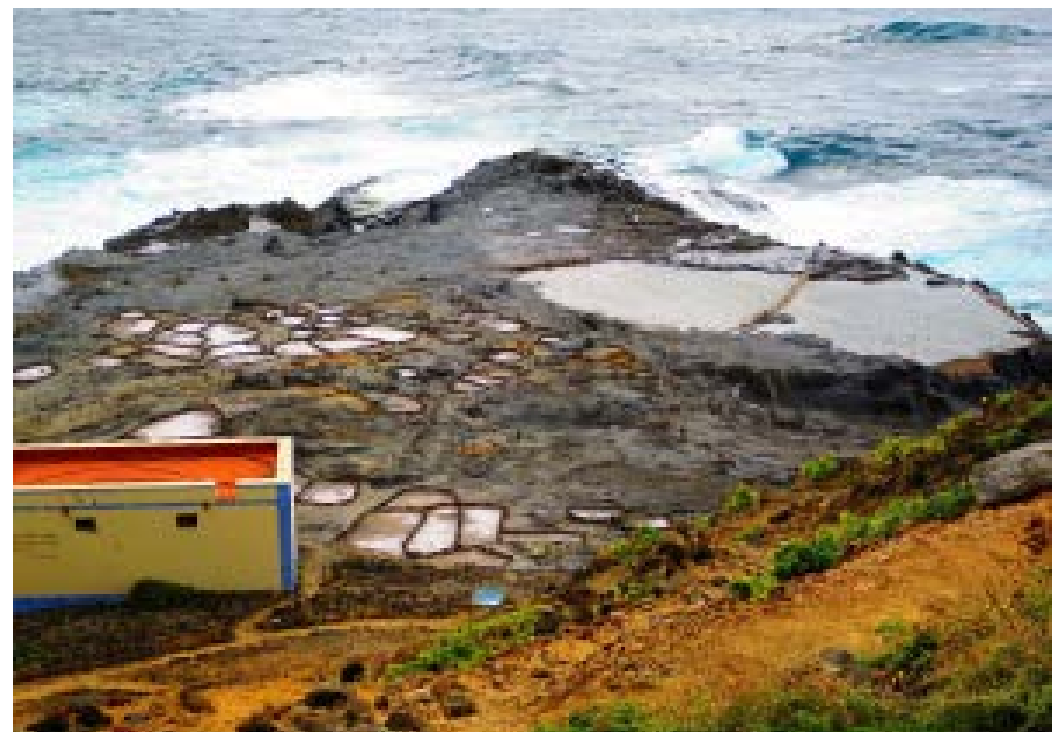

Figura 5: Salinas del Bufadero (Fuente: Foto del autor)

Todas estas salinas suelen ser hechas sobre barro, aspecto común en las salinas de Gran Canaria, excepto las de Arucas que se fabricaron sobre roca donde cristaliza la sal, para formar un verdadero endemismo etnográfico, único a nivel mundial. Produce cloruro sódico de especiales atribuciones nutritivas y organolépticas, es lo que se denomina flor de sal, que adquiere un color rojizo debido a un microorganismo denominado la Artemia salina y le confieren ese llamativo aspecto. 
En alguna ocasión hubo incursiones piráticas, mayoritariamente durante el siglo XVII, que asaltaron estos emplazamientos porque se encontraban en la costa, aunque no todas consiguieron su objetivo. Por ejemplo, en septiembre de 1627 llegó a la playa de las Conchas ( situada entre Maspalomas y Arguineguín), una galeota de turcos que venía de capturar cristianos en Lanzarote y en las salinas de Agüimes y que pretendía hacer lo mismo en ese lugar, para aprovisionarse de agua. La noticia del desembarco de veinte corsarios llegó al capitán Pedro López Trejo, que organizó las compañías de la villa de Agüimes y atacó la incursión enemiga durante la media noche al grito de "Santiago", que acabó con la muerte de la mitad de los asaltantes y apresando al resto. ${ }^{8}$ Para defenderse de esos ataques piráticos fue erigido el Castillo del Romeral, topónimo que se mantiene en dicho pago hasta nuestros días, aunque ya la edificación haya desaparecido.

En 1787 se produce una polémica por la construcción de salinas en el sur de Gran Canaria. El Coronel don José de la Rocha pone una demanda contra el Conde de la Vega Grande, para que suspendiera la fabricación de una nueva salina. El Capitán don Antonio Lorenzo de Betancourt (bisabuelo del coronel don José de la Rocha), Regidor Perpetuo de la isla, había obtenido un permiso el 16 de noviembre de 1673 y había construido unas salinas. Posteriormente, por Real Cédula del 22 de marzo de 1677, tuvo que edificar a expensas suyas una fortificación en la zona para defender la isla de posibles arribadas por mar. El caso es que todos esos terrenos pertenecían al Conde de la Vega Grande, quien ya tenía unas salinas de su propiedad que eran de mayor extensión, llamadas de Balcázar. Todo ese territorio del sur de Gran Canaria desde esta zona en litigio hasta Arguineguín era propiedad de dicho Conde. Éste estaba proyectando hacer otras salinas que impedían al Coronel Rocha la posibilidad de extender las suyas, por lo que Rocha solicitó a la Real Audiencia que obligase al Conde a suspender sus obras, como finalmente se hizo. Pero el Conde de la Vega Grande comenzó su construcción que impedía la extensión de las salinas del Coronel hacia el norte y contravenía la resolución tomada. ${ }^{9}$

La parte litigante alegaba que el Conde tenía esas tierras baldías y continuó solicitando la paralización de las obras bajo el argumento de:

...creciendo de este modo y aumentándose las Salinas en esta Isla, hasta el punto de proporcionarse cómodamente, todo lo que consume de dicho abasto sin necesidad de sufrir un comercio pasivo para proveerse como totalmente se experimenta; y para lo que igualmente conduce, que no sea uno el dueño principal de este ramo... ${ }^{10}$

\footnotetext{
${ }^{8}$ AA. Invasiones, s./fol.

${ }^{9}$ AHPLP. Fondo Real Audiencia, Expediente 1.222, Año 1787, s/fol.

${ }^{10}$ AHPLP. Fondo Real Audiencia, Expediente 1.222, Año 1787, s/fol.
} 
Finalmente, el Conde de la Vega Grande mandó a parar las obras y cuando las autoridades se dirigieron al paraje que llamaban Barco Quebrado no encontraron nada.

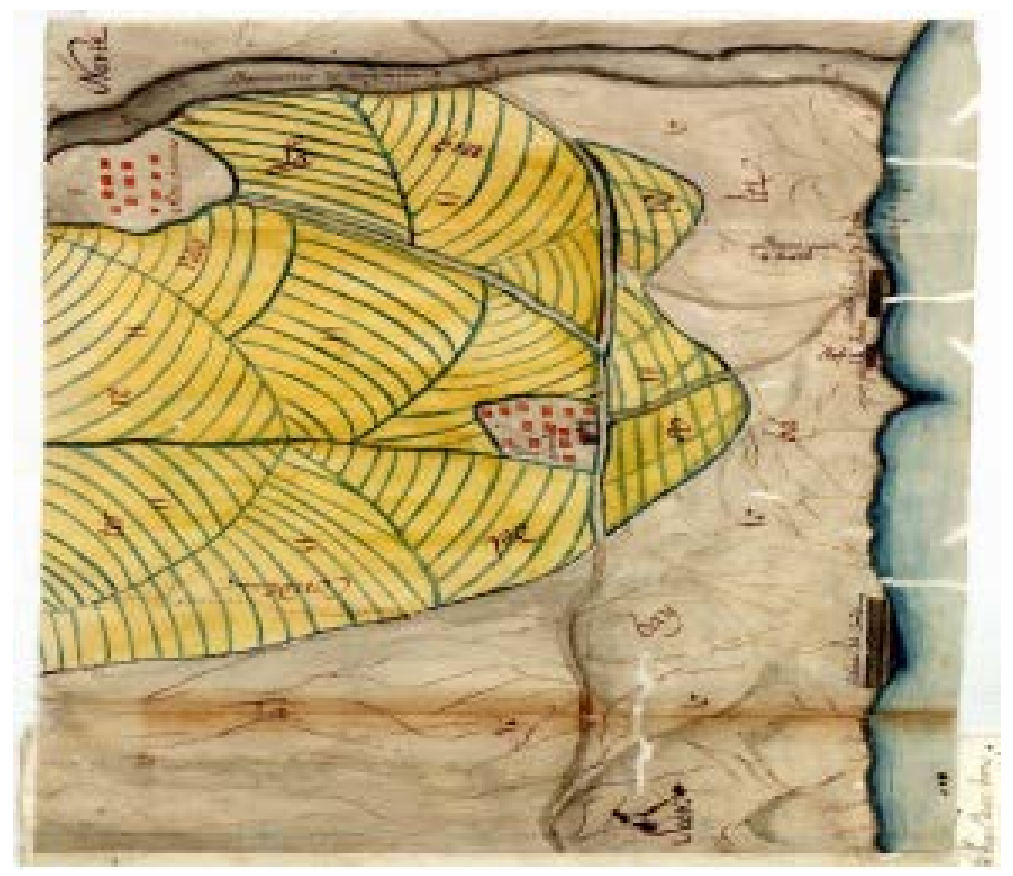

Figura 6: Plano de las salinas del Este de Gran Canaria que ocasionaron el pleito entre el Conde la Vega Grande y el Coronel José de la Rocha (Fuente: AHPLP, Fondo Real Audiencia, Expediente 1.222, Año 1787, s/fol.).

En Lanzarote, las salinas estaban situadas en la parte norte, pertenecientes al Señor de la isla, rematadas en 1.250 pesos. Se encontraban en la caleta de Famara, entre las fuentes de Zafantía y Agura, ${ }^{11}$ datan de principios del siglo XVI. Dado los riscos escarpados y el predominio de las marejadas en la zona, tenían la ventaja de estar ubicadas justamente en las zonas que permitían el acceso por mar, cerca de un espacioso puerto llamado El Río, además de encontrarse cerca de la capital de la isla, la Villa de Teguise. Estuvieron funcionando hasta finales del siglo XIX en que se abandonaron.

\footnotetext{
"Archivo General de Simancas (AGS). Secretaría de Guerra, Guerra Moderna, Leg. 3797, Expediente1, s/fol. Estos datos aluden concretamente al año 1772. De estas salinas se dice que eran las mejores de toda Canarias y de aquí se exportaba sal hacia Tenerife. "Como no la arrendaron los naturales ningún comercio pueden hacer éstos ni tienen otra utilidad que la que les deja a los pobres jornaleros su trabajo personal" que consistía tan sólo en tres reales corrientes. Compendio brebe y famosso, histórico y político, en que [se] contiene la cituazion, poblacion, division, gobierno, produziones, fabricas y comercio que tiene la Ysla de Lanzarote en el año 1776 (Caballero Mujica, 1991, p. 16, 28 y30).
} 
Estas salinas, que se denominan de La Graciosa o del Río según documentos, tenían una importante producción que generaba aproximadamente diez mil pesos anuales, porque se trataba en realidad de dos complejos a los que se unía otro más antiguo. Sufrieron algún deterioro por las embestidas del océano, por lo que se hacían necesarios trabajos de reparación de las murallas que contenían las subidas del mar. En algunas crecientes de mareas irregulares habían quedado destrozados los tajos y cocederos, particularmente a partir de un temporal acaecido en 1756. La reparación fue encargada a Juan Lorenzo quien debía construir la antigua muralla por 3.200 pesos, ajuste que quedaba especificado en la Declaración del Perito. De nuevo, en 1771, otra crecida arruinó las viejas construcciones, que todavía en 1781 no habían sido convenientemente reparadas: el deterioro era tal que imposibilitaba hacerlas idénticas a las anteriores; hasta los cimientos habían sido afectados por lo que de esta antigua construcción no se estaba obteniendo sal alguna. ${ }^{2}$ A finales del siglo XVIII se solicita la creación de nuevas salinas en torno a Arrecife.

Por lo que respecta a Fuerteventura, durante el siglo XVII su importancia fue más reducida y la producción de sal se limitaba a la que se obtenía de algunos charcos de la costa. Los cocederos naturales se situaban en la zona oeste de la isla. Las primeras salinas empezaron a ser construidas en 1681 por don Fernando Mathías, concretamente en Gran Tarajal. Pero no se terminaron nunca. A principios del siglo XVIII era poca la cantidad de sal que se obtenía en cocederos naturales, por eso el Cabildo prohibía la exportación, argumentando que no era suficiente para cubrir las necesidades insulares, lo que hacía preciso incluso recurrir a importaciones. Algunos de esos cocederos que aún se conservan son los de Puerto de la Cruz y de Pasito Blanco.

Además, estipulan que ninguna persona pueda obtener al día más cantidad que la que necesita para el consumo familiar y si cogiese de más, cualquier otro vecino tendría derecho a comprársela a tres reales la fanega. Podemos encontrar varias referencias en el mismo sentido a medida que avanza la centuria, concretamente en los años 1735, 1738, 1754 y 1755. A principios de la década de los ochenta, un vecino de Gran Canaria, el capitán don Juan Francisco del Castillo Olivares solicitó permiso para abrir unas salinas de barro en La Hondurilla, actualmente se conocen como salinas del Carmen. Los autos del pleito que se presentó ante la Real Audiencia el 29 de julio de 1784 señalan que:

... teniendo en consideración la grande utilidad que resulta a esta Provincia de la construcción y fábrica de dichas Salinas y el ningún perjuicio que de ello se sigue en el día a el Don Juan del Castillo según la Diligencia de pericia sin perjuicio de la propiedad del sitio y demás que se ventila; se concede licencia a el Don Francias Bautista para la

${ }^{12}$ AHPLP. Fondo Real Audiencia, Expediente 507, Año 1769, fol. 1 v-99 v, se habla específicamente de la reparación en fol. 94 r-v. 
continuación de dicha Fábrica llevando cuenta y razón de los costos precedida la fianza que ofrece para en el caso que obtenga... ${ }^{13}$

Las salinas que hoy se conservan datan ya del siglo XX, situadas entre Caleta de Fustes y las actuales salinas del Carmen. Pero dicho permiso fue impugnado por el Señor de la isla, don Francisco Bautista de Lugo y Saavedra, natural de Tenerife, quien alegó tener derechos por facultad real otorgada a su antepasado don Fernando Mathías Arias y Saavedra en 1677. Otra escritura de 1681 habla de un terreno en la marisma de Gran Tarajal, colindante con la zona donde don Fernando Mathías estaba fabricando unas salinas como recoge el acta del Cabildo de 1 de septiembre de 1700. En términos parecidos se expresó el Cabildo en sesión del 13 de enero de 1727 . El autor de la edición de las actas afirma en una nota a pie de página que no había salinas en Fuerteventura en esta época, pero en 1789 ya detecta cuatro, además señala tres en Gran Canaria y una en Lanzarote, cifras que según nuestra investigación son inferiores a las reales. Sobre esta última construcción, afirma que no se terminó. También es destacable que hubo prohibiciones por parte del cabildo majorero contra la extracción de sal hacia fuera de la isla, como ocurrió en el acuerdo de enero de 1735. Años más tarde, el l de enero de 1754, se constata que vienen barcos de Gran Canaria a aprovisionarse de sal (Roldán, 1967, p. 88-91, 163, 275).

En las Canarias Occidentales prácticamente era inexistente la producción de sal, excepto alguna pequeña salina que no cubría ni la demanda local. En Tenerife sabemos que hubo algunas en la costa de Los Silos, construidas a fines del siglo XVIII, existieron hasta la presente centuria, pero no se detectan restos hoy en día.

En La Palma a principios del siglo XVIII se construyeron unas salinas en Los Cancajos, que pertenecían originariamente al Mayorazgo de los Fierro y respondían al modelo de salina antigua de mortero de cal, con una superficie de 4.200 metros cuadrados. A ello habría que añadir cantidades de sal obtenidas en los cocederos naturales. Con todo, esta isla fue siempre deficitaria en sal.

En El Hierro se localizaron salinas en Punta Grande, en El Golfo, al pie de los acantilados. Se construyeron en 1680, y se presentaban una extensión de 460 metros cuadrados. Las de Timijiraque datan de la segunda mitad del siglo XVII, y su extensión alcanzaba 780 metros cuadrados. La salina de El Golfo se componía de dos grandes estanques, el cocedero, y fuertes murallas argamasadas. El agua penetraba en la pleamar, recogía unas tres mil pipas por una acequia labrada, de ahí se subía, por medio de una bomba movida por el viento, al segundo estanque y al cocedero. Las salinas de Timijiraque fueron hechas por don Felipe Bueno. También contaban con una bomba manual, encajonada fuertemente en el agujero de una roca que corresponde a un calentoncillo para transportar el agua del mar al estanque. De ahí se sube

${ }^{13}$ Archivo de la Biblioteca de Santa Cruz de Tenerife (ABMS/CT). Caja 80-2, Justicia 10, fol. 1 v-2 r. 
por otra bomba al cocedero de donde se reparte a los tajos, dando una producción total de treinta a cuarenta fanegas de sal. Pero según Urtusáustegui, en 1779, aunque la isla no tuviese salinas no necesitaba importar porque era suficiente para la población, con la que se recogía de las lajas y charcos de la Dehesa y, sobre todo, de los Roques de Salmor que ascendía a tres o cuatro cahíces. Escribe este personaje que en el momento de su viaje debía haber aproximadamente cien tajos y que se seguían construyendo, pero que todo el trabajo y la inversión que ascendía a unos tres mil pesos no los hacían rentables. De las salinas de Timijiraque nos dice que los tajos eran muy pequeños y mal fabricados (Urtusáustegui, 1983, p. 35, 36, 50). ${ }^{14}$

A La Gomera, la sal llegaba mayoritariamente desde Lanzarote a cambio de vino, saliendo por los puertos de Janubio, Arrecife, Escondido y Rubicón. Pero también se recogían pequeñas cantidades en Las Puntas de Las Salinas, en Chipude con una producción en el siglo XVIII de diez a 15 fanegas anuales y, también, en Taguluche donde llegaban a cinco ó seis fanegas, Epina, Alojera de la que se dice que "producía la suficiente sal para un trimestre”, Arguamul con un pequeño superávit que servía para comercialización en el mercado interno y Puntallana (Bory de Saint-Vincent, 1988, p. 125, 147; Luengo e Marín, 1994, p. 31, 32; Díaz e Rodríguez, 1990, p. 342).

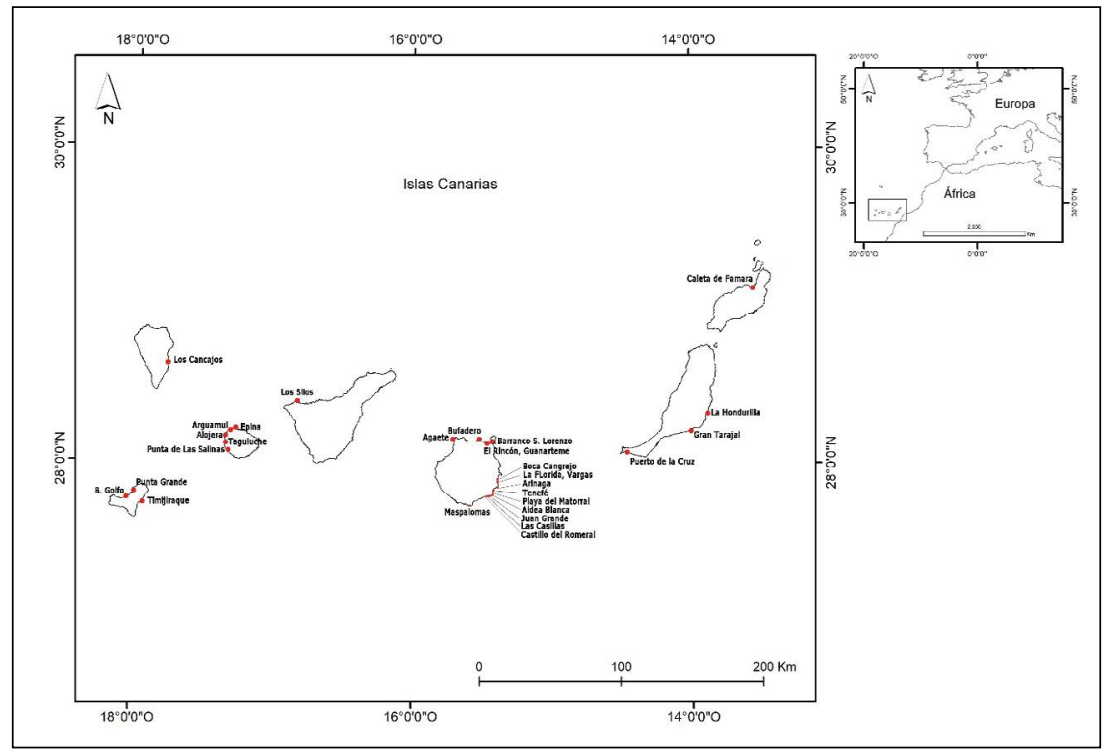

Figura 7: Mapa de salinas canarias (Fuente: Elaboración propia).

${ }^{14}$ En el estudio a esta obra que hace Manuel J. Lorenzo Perera (1983, p. 130), añade: "Hemos visto a las mujeres de los pastores recoger la sal de lajas y charcos costeros para fabricar el queso, principalmente en La Dehesa Comunal (Zona de Los Negros), transportándola sobre la cabeza hasta los lugares de habitación (Montaña del Caracol, de La Cuevas), discurriendo por duras y escarpadas veredas." 


\section{Comercialización}

A pesar de las salinas que se localizaban en Gran Canaria, que producía más cantidad, durante los siglos XVII y XVIII casi la práctica totalidad del comercio de sal a nivel regional en el archipiélago canario estuvo protagonizado por Lanzarote. Esta última isla era claramente excedentaria en relación a su escasa población.

La producción de sal grancanaria se destinaba sobre todo al consumo interno de su población y a las pesquerías. No obstante, es posible que en alguna ocasión también se transportase sal de esta isla a Tenerife o a La Palma, tal y como apunta George Glas para mediados del siglo XVIII (Glas, 1982, p. 138), este autor menciona que desde Gran Canaria se exporta a Tenerife, entre otros artículos, cierta cantidad de sal. Apenas se exportó sal desde Gran Canaria como podemos observar a través de las aduanas de la isla en 1792 y 1793 , únicamente hubo un envío de quinientas fanegas de sal hacia La Habana, que es el único que aparece reflejado hacia el continente americano en todo el Antiguo Régimen, con lo que debemos concluir que o bien es un caso esporádico o tal vez un reenvío procedente de la Península con escala en Canarias (Santana, 2004, p. 898). Desde Fuerteventura el cabildo majorero prohibió a principios del siglo XVII que se exportase sal con el argumento de la necesidad de abastecer el mercado interior. Este mismo impedimento fue reiterado a principios del siglo XVIII con justificaciones similares, incluso alegan que se había hecho preciso recurrir a las importaciones (Roldán, 1967, t. I, p. 252; t. II, p. 275).

Algunas de las islas destacaban a los ojos foráneos por su producción de sal. Así, el humanista portugués Gaspar de Fructuoso señalaba en el siglo XVI que "en estas islas se hace sal muy blanca", refiriéndose a la calidad de la de Lanzarote (Fructuoso, 1964, p.98) y en una descripción que realiza el cónsul francés en Canarias, Jean de Radedante, en julio de 1686, dice de Lanzarote: "es muy fértil en granos de trigo y en sal."15 En la segunda mitad del siglo XVII, parece que se da un incremento de la producción y, por tanto, de la comercialización, ocasionado por la subida de precios, por el progreso de las pesquerías y de la navegación y por el aumento de la población en Canarias. Habrá que esperar a la segunda mitad del siglo XVIII para que se intente dar un nuevo impulso a las pesquerías y con ellas a la salazón del pescado.

En Lanzarote a principios del siglo XVII la producción anual era en torno a los cuatrocientos cahíces (Macías, 1989, p. 158), de 12 fanegas cada cahíz. Los portugueses tienen documentación de 1606 señalando que se han fabricado unas salinas en Arrecife con una producción cifrada entre tres mil y cuatro mil cahíces anuales. Además, dicen que hay una propuesta de construir otras salinas en el Puerto de Janubio (Silveira, 1954, p. 19-25).

${ }^{15}$ Centre d'Accueil et de Recherche des Archives Nationales, París (Caran). Affaires Étrangères, B///1072. 
Desde esta isla se abastecía de sal a otras islas. La sal lanzaroteña llegaba a Gran Canaria, Tenerife, La Palma y La Gomera. Hacia Tenerife iba la mayor parte de la comercialización de la sal lanzaroteña, debido al déficit generado por su mayor población y a la escasez de salinas. El segundo lugar lo ocupaba Gran Canaria, no sólo por su población sino también por su vocación pesquera hacia Berbería, seguida de La Palma. No debemos descartar que la sal lanzaroteña también se emplease en el aprovisionamiento de navíos que hacían escala en las islas centrales con destino a lugares lejanos, ya que formaba parte de la alimentación de la marinería de forma habitual.

Esta sal era empleada en el abastecimiento del mercado interno canario, generalmente por el Puerto de Naos. Sabemos que, en 1798, aparte de algunos cargamentos particulares, fueron exportados 49.373 quintales de sal a Tenerife como nos dice un viajero francés a principios del siglo XIX (Bory de Saint-Vincent, 1988, p. 120).

En el comercio de sal participan importantes mercaderes de las islas, algunos de origen foráneo, ${ }^{16}$ aunque la mayoría eran canarios o asentados en Canarias. La sal, en muchos casos, va por cuenta de personajes importantes, que ocupan cargos dentro del archipiélago, como procuradores de la Audiencia, regidores, almojarifes, o el arrendador del Estado en Lanzarote. Conviene resaltar el papel de los marqueses de Lanzarote, en estrecha relación con las salinas, al igual que otros como el deán, los miembros del cabildo o el mismo obispo de Canarias a través de la comercialización del diezmo. ${ }^{17}$

Es muy difícil precisar cuáles son las cantidades que se comercializan, ya que raramente se nos indica el montante total de sal transportado en una embarcación, ni para las importaciones externas ni para el tráfico regional. Si a eso unimos nuestras limitaciones para conocer el total de producción de las salinas y su evolución durante dos siglos, se comprende el que no se puedan establecer series creíbles y que recurramos únicamente a las estimaciones para comparar unos periodos con otros.

La producción de sal en Canarias no era mayor porque chocaba con los intereses de la Corona. Asistimos al primer gran desarrollo de los diversos ingenios salineros en Canarias. Tanto es así que a finales del siglo XVIII se deniegan curiosamente nuevas solicitudes bajo el pretexto de que la creciente producción de sal y su posible destino al continente ameri-

\footnotetext{
${ }^{16}$ AHPLP. Escribano Ortega, Francisco, leg. 1.415, año 1697, fol. 104 r-v. El 9 de marzo de 1697, Guillermo Nicolás, un inglés que vivía en la ciudad de Las Palmas declaró que debía al mercader de la misma ciudad, Francisco Mustelier, 3111 reales en moneda de plata por la compra de 403,5 fanegas de sal que remitió al Puerto de Santa Cruz. También debía otros 635 reales a otro inglés avecindado en Santa Cruz de La Palma, Enrique Bolton, por el resto de sal.

${ }^{17}$ AHPLP. Escribano Alonso Hernández, Juan, leg. 2731, año 1621, Lanzarote, fols. 497 v-498 v. En octubre de 1630, Juan Duin, de La Orotava, maestre y señor del patache La Esperanza y el Buen Viaje, la fletó al licenciado Lucas Andrés, racionero de la catedral y hacedor de Lanzarote y Fuerteventura, que actuaba en nombre del Deán y del Cabildo para recibir en Lanzarote doscientas fanegas de sal en las salinas y llevarlas a Gran Canaria a la caleta de Santa Ana.
} 
cano podrían competir con las extracciones de sales de La Mata y la Bahía de Cádiz, dos de los baluartes del monopolio real español (Luengo e Marín, 1994, p. 25; abordan cada una de las salinas en p. 143-154).

La sal en el resto de la Corona española estuvo entre los estancos o monopolios de la fiscalidad del siglo XVIII, pero no en Canarias. Su producción, distribución y consumo estuvo sometido, en la mayor parte de Europa, a ordenamientos y reglamentaciones gubernamentales, lo que proporcionaba pingües beneficios (Cremades, 1988, p. 880-882). El más famoso de estos impuestos fue la gabela, que se aplicaba en Francia. Tenemos anotaciones a las rentas estancadas en el siglo XVIII entre las que se hallaba la sal y como los sobreprecios sobre este producto fueron cosa corriente en los momentos de crisis. Por ejemplo, durante la guerra contra Inglaterra en 1779 duplica el precio por fanega (Artola, 1982, p. 356).

Desde 1564 Felipe II había retomado la política del monopolio regio de las salinas, así incorporó al patrimonio real todas las salinas del reino de Castilla con la excepción de las andaluzas y las canarias. Durante el siglo anterior, la Corona castellana había logrado hacerse con algunas salinas de propiedad particular, pero también había ido cediendo otras a renombrados aristócratas. Con esta nueva ley se puso en marcha el nuevo sistema de estanco, que perduró en toda la Edad Moderna, por el que la Corona se reservaba la fabricación y venta de sal. De este modo no podría trabajarse la sal fuera de los lugares a los que el rey otorgase licencia para ello (Porres, 2007a, p. 35-36).

Durante el siglo XVII Felipe IV aplicó una gravosa política sobre la sal. La nueva ley conservaría la de incorporación que había aplicado su abuelo (Porres, 2007b, p. 343-385), esta autora sostiene que es novedosa la prohibición de salar el pescado con agua de mar, pero ya había sido promulgado por Felipe II en 1586, retomando una ley de Juan II de 1409. Además, en Canarias uno de los conceptos que incluía las tercias de Castilla era el de tercias de la sal de Gran Canaria (Solbes, 2009, p. 67).

Los libros de almojarifazgos revelan que en 1664 arribaron a Gran Canaria, en tres navíos, 434 fanegas de sal procedente de Cádiz. ${ }^{18}$ Esta tendencia continuó durante el siglo XVIII ya que en la segunda mitad de la centuria continuaba entrando en el puerto de La Luz este artículo desde dicha ciudad andaluza (Suárez, 1982, p. 166, 167, 180).

Hay que tener en cuenta que, en las importaciones de sal, de manera frecuente no se menciona el montante de la carga. A diferencia del tráfico regional, en las importaciones de sal peninsulares tienen mayor protagonismo los mercaderes foráneos. Lo mismo ocurre con los maestres de las embarcaciones, al menos en el siglo XVII. ${ }^{19}$

\footnotetext{
${ }^{18}$ AGS. Contaduría Mayor de Cuentas, leg. 3190, no 2. El 24 de noviembre desembarcó el navío Juan y María, de Cádiz, entre otras mercancías, trecientas fanegas de sal.

${ }^{19}$ Archivo del Museo Canario (AMC). Sig: CLXIII Leg. 46. En marzo de 1644 llegó al puerto de La Luz el navío Juana María, procedente de Cádiz con carga de sal, medias de seda, sombreros, damascos de todos los colores que venían a cargo de los mercaderes ingleses que venían también en el navío.
} 
La sal importada de la Península fue minoritaria en comparación con el comercio que se estableció a nivel regional o insular en el archipiélago. Sin embargo, era transportada en embarcaciones de mayor tonelaje de las que habitualmente participaban en el comercio canario, por lo que las cantidades llegadas en un sólo viaje eran mayores. Igual ocurría en otras latitudes, como vemos por ejemplo en el modelo del comercio de sal en el Mediterráneo propuesto por Hocquet (1979, p. 128-134), es decir, cuanto más lejana era la distancia a recorrer por la sal, mayor era la carga depositada en la embarcación. En efecto, como ha apuntado este autor, una nave de pequeño tonelaje no iba a encontrar gran beneficio en transportar unas pocas fanegas de sal desde lugares muy lejanos. Por el contrario, el número de viajes regionales, teniendo un tonelaje aún menor, serían más abundantes.

Además de los centros peninsulares también se introdujo sal desde otros puntos del Mediterráneo, aunque con carácter ocasional. Uno de ellos fue Malta desde donde se embarcaron hacia Gran Canaria, junto con otras mercancías quinientas fanegas de sal a finales del siglo XVIII. Existe un trabajo muy completo sobre los malteses en España en el siglo XVIII, pero que no recoge estas partidas de sal (Vassallo, 1997).

Contamos con la evolución de los precios de la fanega de sal en la isla de Fuerteventura, dado que su Cabildo lo regulaba y trataba el tema con cierta regularidad a lo largo del siglo XVIII. Podemos ver que son inferiores a los diez o nueve reales en los que había quedado establecido su precio para el resto de la Corona española. Generalmente había un precio en la zona en que se cogía la sal y otro en los pueblos interiores, normalmente doble, pero en ocasiones mantuvo el mismo valor.

Podemos conocer el precio de la fanega de sal en Fuerteventura entre 1735 y 1793, casi siempre mantuvo en tres reales en la marina, donde se obtenía sal y de seis en los otros lugares de la isla. Sólo hubo dos momentos en que subió el precio en las salinas, que, a juzgar por los datos dispersos, debemos entender que abarcaría desde 1738 a 1750 y de 1750 a 1754 , que bajó en los pueblos majoreros a casi la mitad. ${ }^{20}$

\section{Relaciones con la sal de la Corona portuguesa}

Desde el siglo XVI diversas embarcaciones europeas arribaban a Cabo Verde a cargar sal, concretamente en las islas de Maio, Boavista y Sal (Brooks, 2006, p. 113).En Maio la sal estaba en manos de extranjeros, sobre todo ingleses, pero no hubo esfuerzos por mejorar la producción de esa salina (Pereira, 1984, p. 146). Canarias se vio obligada a importar sal de otras áreas africanas. Desde el archipiélago de Cabo Verde hubo diversos envíos, específi-

${ }^{20}$ Acuerdos del Cabildo de Fuerteventura (Roldán, 1967). 
camente con las islas de Sal y de Maio, que contaban con instalaciones salineras de consideración, algunas de las cuales se han conservado hasta la actualidad. Durante el siglo XVII, la más importante en el tráfico internacional de sal fue la isla de Maio, un tráfico dirigido principalmente hacia América del Norte, dedicado a la salazón de bacalao. Con todo, estas islas eran más pobres y estaban menos pobladas que la de Santiago (Santana e Santana, 2002, p. 187-188), donde estaba su capital. Hacía 1699, la isla de Maio, la más poblada, de las que destacaba por su producción de sal, tenía sólo unos 230 habitantes. Igualmente, en el siglo XVIII, también se envía sal a Canarias. ${ }^{21}$

Sin embargo, a pesar de las salinas canarias, la producción total del archipiélago era deficitaria y se tenía que importar, principalmente desde Andalucía y Portugal (Langsdorff, 1991, p. 67). ${ }^{22}$ La necesidad de sal motivó en alguna coyuntura que se aprovechase el paso de alguna embarcación que tenía otro destino. Así el 27 de mayo de 1635 llegó al puerto de Santa Cruz de Tenerife un navío que iba para Brasil, cargado de seiscientas fanegas de sal. Al hacer falta en Tenerife se descargaron y vendieron en su totalidad en la isla. ${ }^{23}$ Hemos hallado otras referencias parecidas, como la entrada de dos barcos de Madeira y uno de Lisboa que entre otros géneros traían sal al puerto de Luz en Gran Canaria (Romero, 2002, p. 278). También sabemos que en 1801 la aduana de Santa Cruz de Tenerife importó 3.339 fanegas de sal de Portugal a veinte maravedís. ${ }^{24}$

A finales del siglo XVIII Cabo Verde es el tercer abastecedor exterior de sal de Tenerife, después de Cádiz y Lisboa y los envíos de este artículo son más regulares que en épocas anteriores. Las remesas aportadas en cada viaje solían ser menores de mil fanegas por embarcación. Las islas de Cabo Verde abastecían de sal en la segunda mitad del siglo XVIII también a otros archipiélagos atlánticos como Madeira. Concretamente sabemos que iban a buscar sal a Maio (Ribeiro, 1993, p. 705). No debemos descartar que saliese sal desde otras islas caboverdianas como la propia isla de Sal, cuyo topónimo ya es indicativo. Si bien es verdad que hemos hallado un envío de sal desde Madeira a Santa Cruz de Tenerife, éste se nos antoja más anecdótico y quizás más bien fruto de la redistribución que representativo de la tónica real en el comercio, ya que además se trata de una cantidad pequeña.

Los contactos con Cabo Verde continuaron realizándose casi siempre a través de por-

\footnotetext{
${ }^{21}$ Caran. Affaires Étrangéres, B/III/351, s./fol. Entre el cargamento de la goleta portuguesa El Santo Espíritu, que llegó de Cabo Verde a Tenerife en abril de 1790, se hallaban quinientas fanegas de sal.

22 Este viajero cuenta que se enteró que traían sal de Portugal, no hace alusión a la que procedía del resto de la Corona española. En un pleito ante la Real Audiencia encontramos referencias en el mismo sentido de señalar el déficit de sal de Canarias, AHPLP. Fondo Real Audiencia, Expediente1.222, Año 1787, s/fol.

${ }^{23}$ Archivo Municipal (AMLL). Causas por fieles ejecutores 1, cuadernillo 3. s/fol.

${ }^{24}$ Esto lo podemos constatar en Estadística de las Islas Canarias, 1793-1806. De Francisco Escolar y Serrano. Transcripción documental, t. III, p. 466 (1983).
} 
tugueses. No obstante, algunas embarcaciones estadounidenses, francesas o inglesas, cargadas con vino canario, también se aventuraban a llevarlo, ${ }^{25}$ para luego cargar sal, entre otros artículos. Luego la sal era transportada a sus países de origen, y así se articulaba un comercio atlántico a varias bandas que iba incrementando el nivel de ganancia en cada parada. La presencia de los españoles estuvo también asegurada. En la isla de Sal el comerciante portugués Manuel Martins comenzó la explotación de la salina de Pedra de Lume en 1804, llegó a convertirse en un gran exportador de sal hacia Brasil, y en 1835 puso en funcionamiento las salinas de Santa María en la misma isla (Menéndez, 2008, p. 85).

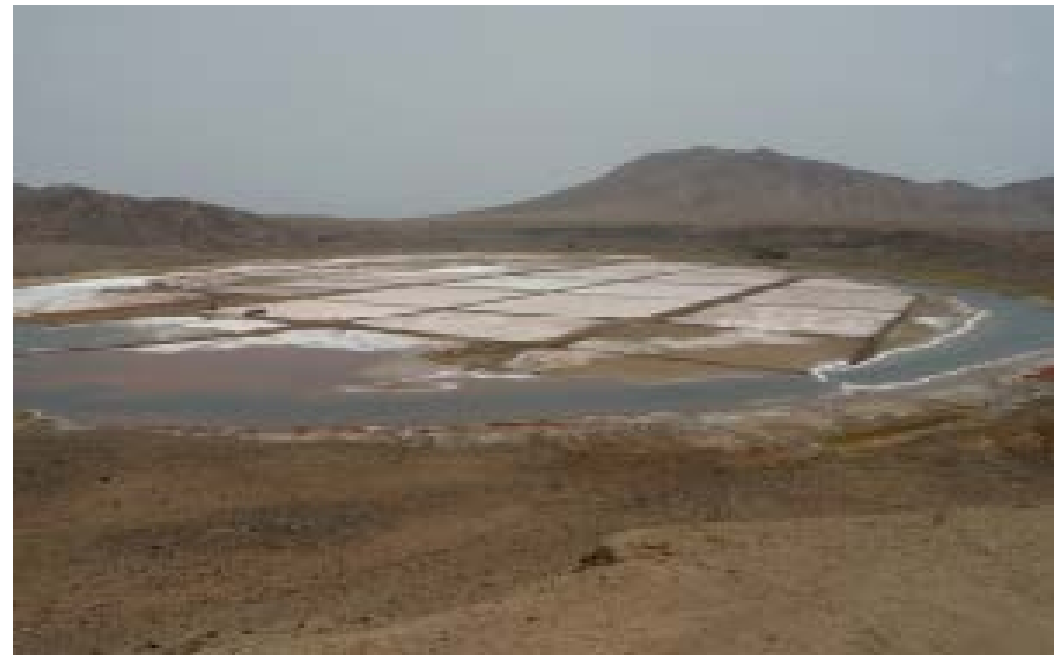

Figura 8: Salinas de Pedra Lume en isla de Sal, Cabo Verde (Fuente: Foto del autor).

En la aduana portuaria de la isla de Santiago, donde estaba la capital archipiélago, encontramos muchos barcos con sal para esta isla o que hacen escala en esta isla, con dirección a otros destinos más alejados, como el 30 de marzo de 1820 un bergantín americano destino a Nueva York, el 11 de diciembre de 1821 procedente de la isla de Maio, el 28 de septiembre de 1824 exportando sal a Boston, el 2 de mayo de 1825 con sal hacia Nueva York, el 20 de junio de 1826 otra embarcación norteamericana procedente de Nueva York, tras haber pasado por Madeira y la isla de Maio con carga de sal y que hizo aguada en Santiago y el 23 de junio de 1826 otro brique americano de Maio que llega a Santiago. ${ }^{26}$

\footnotetext{
${ }^{25}$ Caran. Affaires Étrangères, B/III/350, s./fol. En marzo de 1786 los navíos americanos El Ranger y La Tomasa, cargaron en Santa Cruz de Tenerife 15 y diez pipas de vino respectivamente para llevarlas a Cabo Verde.

${ }^{26}$ Archivo Nacional de Cabo Verde (ANCV). Fondo Secretaría Geral do Governo. SGG/G.4/Lv0956, entrada dos navios do Porto de Praia, fol. 39 r-66 r.
} 


\section{Proyectos ilustrados}

Hacia fines del siglo XVIII se idearon en los archipiélagos atlánticos algunos proyectos de pesquerías y de salinas para salar los pescados, aunque la mayor parte de ellos no llegaron a culminarse, es bien conocido el caso de Madeira (Afonso, 1995, p. 84-92) que guardaba similitudes con Canarias. La Real Sociedad Económica de Amigos del País de Las Palmas trató el tema en la junta del 19 de mayo de 1783, donde don Antonio de Franchy expuso que estaba dispuesto a emprender la construcción de nuevas salinas en las playas de San Cristóbal, en las afueras de la ciudad, o en las playas de Gando, al este de esta isla y a mayor distancia. El proyecto parecía asequible y los ilustrados canarios veían una posibilidad para que la producción insular abasteciese al archipiélago en la salazón de sama y de tasarte, con lo que se reducirían las importaciones de la Península. También otro miembro de los Amigos del País, Cipriano Avilés, proponía fabricar otras salinas en la zona de la Isleta. Por ello, la Sociedad Económica comisionó a estos dos socios para que presentasen sus ideas por escrito, resaltando las utilidades públicas y la calidad de la sal, para estudiar qué apoyos podrían prestar los Amigos del País y lo que podrían obtener de los poderes públicos. Las memorias fueron presentadas el 25 de agosto del mismo año, junto con muestras de sal que habían producido de forma experimental en Gando. La calidad pareció aceptable (Viera, 1981, p. 86). En 1785 Cristóbal Vicente Mujica solicitó al Concejo de Gran Canaria una propiedad de La Isleta, para construir unas salinas (Romero, 2002, p. 40). Estos intentos no llegaron a prosperar y no hemos vuelto a encontrar documentación que dé respuestas sobre el tema.

Para fabricar unas salinas marinas rentables era necesario contar con una buena extensión de terreno, es decir, se precisaba una superficie considerable, que debía tener unas condiciones determinadas, como la llanura de esas tierras. Debían estar situadas en la costa, muy cerca del mar, pero a una distancia prudencial que las protegiera del oleaje. Otra particularidad importante es la impermeabilidad, porque en un terreno arenoso se filtraría toda el agua del mar. Por tanto, no toda la costa presenta rasgos favorables a estas construcciones. Las que primeramente fueron utilizadas eran las llamadas cantiles, tipo de costa que se forma en el frente de una colada basáltica al ser erosionada por el mar, dando como resultado un acantilado de pequeña altura que obliga a captar el agua mediante rebosadero o bufadero.

La conservación del pescado en sal debía constituir una industria fundamental en el desarrollo del sector, no podía venderse íntegramente en el mercado, porque sería una mala maniobra empresarial que generaría el hundimiento de los precios. Se hacía preciso desarrollar un sistema de conservación que permitiese llegar a mercados alejados y dilatar el 
periodo de ventas. La solución estaba en la potenciación de la salazón. En la Corona española estos métodos serán fomentados por catalanes (Fernández, 1993, p. 381).

El nuevo método consistía en un prensado mecánico en grandes pilas o lagares, que permitía la extracción de una mayor cantidad de grasa, lo que suponía un ahorro de sal. Lo positivo de las viejas técnicas es que posibilitaban una manipulación casera y familiar del pescado, mientras que las nuevas técnicas de salazón exigían disponer de fábricas adecuadas, con instalaciones de gran capacidad que sólo estaban al alcance de las nuevas compañías capitalistas. La ausencia de compañías de este tipo y de un espíritu empresarial en el sector, hizo que en Canarias fuese difícil su incorporación.

Este método de prensado permitía incrementar la productividad por dos razones: multiplicaba la producción y reducía la mano de obra en el proceso de salazón. Todo ello hacía que el nuevo producto conservero fuese altamente competitivo (Urteaga, 1987, p. 44).

El éxito de estas empresas en la Península, hizo que en Canarias se llevasen a cabo tímidos intentos, como los de 1779 por parte de Bartolomé Suárez y Juan de Arucas, que llegaron a comercializar algunas partidas. En 1786 Miguel Camacho lo intentó nuevamente. Sin embargo, todos estos proyectos fracasaron (Martín, 1989, p. 116-117).

En 1774 don Bartolomé Montañez había fabricado unos almacenes en Santa Cruz de Tenerife para salar y secar pescados (Guerra, 2002, p. 342).

Encontraremos nuevas tentativas en 1786, como las de don Ricardo Madan, en Santa Cruz de Tenerife, que seguían a los de don Bartolomé Montañez unos años antes, pero ahora con mejores resultados:

...los experimentos últimamente hechos por un honrado Comerciante y buen Patriota a sus expensas reducidos sustancialmente a variar la disposición del Pescado y el método que se sigue de salazón para lo cual hizo venir Extranjeros inteligentes, y navegó dicho Pescado a varias partes, hasta Buenos Aires, desde estas Islas, donde retornó sin adquirir el rancio, y corrupción que no se pudieron evitar en las experiencias que algunos años antes practicó D. Bartolomé Montañez. Sin embargo, a mi juicio convendría que se repitiesen todavía más los referidos experimentos últimamente practicados por Madan (sin innovar el presente sistema general de salar el Pescado, para no exponer esta islas con su falta a la carencia de este comestible, que como se ha dicho es el alimento general de sus Moradores) hasta que el Gobierno se halle plenamente satisfecho de la mejora y mayor ración del Pescado... ${ }^{27}$

Podemos afirmar que hubo una estrecha interrelación entre la sal y las capturas de la pesca canaria en el banco sahariano, dado que el pescado salado era uno de los platos más

${ }^{27}$ Archivo del Museo Naval (AMN). Manuscrito 1.955, s/fol. 
comunes en nuestras latitudes y no sólo entre las clases bajas. Esto motivó la elaboración de una serie de proyectos para mejorar ambos sectores, el de la sal y el del pescado, pero prácticamente ninguno llegó a prosperar, como ocurrió con tantas propuestas realizadas por los ilustrados en el siglo XVIII. De este modo, vemos que la actividad pesquera propició la aparición de salinas, preferentemente en Gran Canaria, que hacia fines del siglo XVIII podemos considerar como la isla hegemónica en el sector y la de mayor número de salinas y de mayor producción total.

Se han dado diferentes razones para explicar la mala conservación del pescado salado en Canarias. Se ha apuntado el agua empleada y, sobre todo, las técnicas deficientes de salazón. Estamos de acuerdo con estos factores evidentes, pero creemos que al ser las condiciones climáticas más cálidas y, sobre todo, que los pescados obtenidos en el banco sahariano no son bacalaos, la salazón de estas latitudes presentan una composición química que no es idéntica y biológicamente tiene más dificultades de conservación.

\section{Consideraciones finales}

El comercio regional no pudo cubrir las necesidades del consumo canario debido a varias causas. En primer lugar, el monopolio de la Corona española favoreció la producción y la comercialización de sal peninsular, incluso en áreas que potencialmente podían cubrir las necesidades con su propia producción, e incluso exportar. Además, no existió una derivación de capitales suficientes dedicados a la extracción de sal a gran escala, ya que, con todo, y a pesar de las licencias solicitadas durante los siglos XVII y XVIII, su producción siguió siendo insuficiente. El incremento continuo de la población y el desarrollo de las labores de pesca contribuyeron a aumentar el consumo, y a que se continuase trayendo sal del exterior.

Por todo ello, a pesar del carácter insular, Canarias fue deficitaria en el comercio de sal, en buena medida, debido a que la política de la Corona española impedía un mayor desarrollo de esta industria porque chocaba con sus intereses.

\section{Referencias}

AFONSO, João. Salinas e pescarias a haver na ilha da Madeira: Uma documentação doutro tempo e, A(des) propósito, um poema ecológico. Islenha (Madeira). n. 17, p. 84-92, jul.-dez. 1995.

ARTOLA, Miguel. La hacienda del Antiguo Régimen. Madrid: Alianza, 1982.

BORY DE SAINT-VINCENT, Jean-Baptiste G.M.
Ensayos sobre las Islas Afortunadas y la antigua Atlántida o Compendio de la historia general del archipiélago canario. La Orotava: A Través del Tiempo, 1988 [escrito en 1803].

BRAUDEL, Fernand: Civilización material y capitalismo. Barcelona: Labor, 1974.

BROOKS, George E. Cabo Verde: gulag of the South Atlantic: racism, fishing prohibitions, and famines. 
History in Africa (Cambridge, UK). n. 33, p. 101-135, 2006.

CABALLERO MUJICA, Francisco. Introducción y notas.Compendio brebe y famosso, histórico y político, en que [se] contiene la cituazion, poblacion, division, gobierno, produziones, fabricas y comercio que tiene la Ysla de Lanzarote en el año 1776. Las Palmas de Gran Canaria: Ayuntamiento de Teguise, 1991.

CREMADES GRIÑÁN, Carmen María. Las salinas como fuente de riqueza fiscal en el siglo XVIII. Coloquio Internacional Carlos III y su siglo, t. II. Madrid: Universidad Complutense de Madrid, p. 877-893, 1988.

CÚLLEN DEL CASTILLO, Pedro (comp.). Libro rojo de Gran Canaria. Las Palmas de Gran Canaria: Tipografía Alzola, 1947.

DÍAZ PADILLA, Gloria; RODRÍGUEZ YÁNES, José Miguel. El señorío en las Canarias Occidentales: La Gomera y El Hierro hasta 1700. Valverde: Cabildo Insular de El Hierro; San Sebastián de La Gomera: Cabildo Insular de La Gomera, 1990.

ESCOLAR Y SERRANO, Francisco. Estadística de las Islas Canarias. 1793-1806.3 tomos. Transcripción de Germán Hernández Rodríguez. Las Palmas de Gran Canaria: Caja Insular de Ahorros, 1983.

FERNÁNDEZ DÍAZ, Roberto. Manual de Historia de España, siglo XVIII. Madrid: Historia 16, 1993.

FRUCTUOSO, Gaspar de. Las Islas Canarias (De "saudades da terra"). La Laguna: Instituto de Estudios Canarios, 1964 [escrito en 1590].

GLAS, George. Descripción de las Islas Canarias (1764). Santa Cruz de Tenerife: Instituto de Estudios Canarios, 1982 [escrito en 1764].

GÓMEZ MIEDES, Bernardino. Comentarios sobre la sal. Madrid: Edición de Sandra Inés Ramos Maldonado; Instituto de Estudios Humanísticos, 2003. 3 v.

GONZÁLEZ NAVARRO, José. Las salinas tradicionales de Gran Canaria. Las Palmas de Gran Canaria: Fedac, 1996.

GUERRA Y PEÑA, Lope Antonio de la. Memorias: Tenerife en la segunda mitad del siglo XVIII. Las Palmas de Gran Canaria: Cabildo Insular de Gran Canaria, 2002 [escrito en 1760-1791].
HERRERO SÁNCHEZ, Manuel. La explotación de las salinas de Punta de Araya: un factor conflictivo en el proceso de acercamiento hispano-neerlandés (1648-1677). Cuadernos de Historia Moderna (Madrid). n. 14, p. 173-194, 1993.

HOCQUET, Jean-Claude. Le sel et la fortune de Venise. v. 2: Voiliers et commerce en Méditerranée, 1200-1650. Lille: Presses Universitaires de Lille, 1979.

HOCQUET, Jean-Claude. Los puertos de la sal en la Europa meridional: contribución al estudio de las estructuras materiales de un gran comercio. Estudis D'Història Econòmica (Palma de Mallorca).n. 1, p. 5-26, 1988.

KELLENBENZ, Hermann. La técnica en la época de la revolución científica (1500-1700). In: CIPOLLA, Carlo Manuel (org.). Historia económica de Europa, v. 2. Barcelona: Ariel, 1987, p. 141-213.

LANGSDORFF, Georg Heinrich von. Viajes por diferentes partes del mundo durante los años 1803, 1804, 1805, 1806 y 1807. Introducción de Manuel Hernández González, La Orotava: A Través del Tiempo, 1991 [escrito en 1807].

LUENGO, Alberto; MARÍN, Cipriano. El jardín de la sal. Santa Cruz de Tenerife: Gobierno de Canarias y Otras Instituciones, 1994.

MACÍAS HERNÁNDEZ, Antonio Manuel. Un artículo "vital" para la economía canaria: producción y precios de la sal (c. 1500-1836). Anuario de Estudios Atlánticos (Madrid-Las Palmas). n.35, p. 151-215, 1989. MARTÍN CORRALES, Eloy. Atraso tecnológico de la pesca del salado en Canarias en el siglo XVIII. In: PESET, José Luis (org.): Ciencia, vida y espacio en Iberoamérica, v. II. Madrid: Consejo Superior de Investigaciones Científicas, 1989, p. 103-123.

MENÉNDEZ PÉREZ, Emilio. Las rutas de la sal. La Coruña: Netbiblo, 2008.

MOLLAT DU JOURDAIN, Michel. Europa y el mar. Barcelona: Crítica, 1993.

PEREIRA, Daniel A. A situação da Ilha de Santiago no $1^{\underline{0}}$ quartel do século XVIII. Praia: Alfa-Comunicações; Instituto Caboverdiano do Livro, 1984.

PORRES MARIJUÁN, Rosario. Sazón de manjares y 
desazón de contribuyentes: la sal en la Corona de Castilla en tiempos de los Austrias. Bilbao: Universidad del País Vasco, 2003.

PORRES MARIJUÁN, Rosario. Las reales salinas de Añana (siglos $X$-XIX). Bilbao: Universidad del País Vasco, 2007a.

PORRES MARIJUÁN, Rosario. Discursos forales y fiscalidad real: las provincias vascas ante el crecimiento de la sal de 1631. Studia Historica. Historia Moderna (Salamanca). n.29, p. 343-385, 2007b.

PUCHE RIART, Octavio; AYARZAGÜENA SANZ, Mariano; MAZADIEGO MARTÍNEZ, Felipe. Patrimonio salinero español. In: Sociedad Española de Historia de la Arqueología: La explotación histórica de la sal: investigación y puesta en valor. Madrid: Seha, 2009.

RIBEIRO, João Adriano. As relações mercantis entre o Funchal e as Canárias na segunda metade do século XVIII, numa panorámica notarial madeirense. IX Coloquio de Historia Canario-Americana (1990), t. II. Las Palmas de Gran Canaria: Cabildo Insular de Gran Canaria, 1993, p. 59-70.

ROLDÁN VERDEJO, Roberto. Acuerdos del Cabildo de Fuerteventura, 1660-1728. La Laguna: Instituto de Estudios Canarios, 1967.

ROMERO Y CEBALLOS, Isidoro. Diario cronológico histórico de los sucesos elementales, políticos e históricos de esta isla de Gran Canaria (1780-1814), t. I. Edición y estudio de Vicente Suárez Grimón. Las Palmas de Gran Canaria: Cabildo Insular de Gran Canaria, 2002 [escrito en 1780-1814].

SANTANA PÉREZ, Germán. Un estudio del tráfico marítimo canario a finales del siglo XVIII: Gran Canaria en los años 1792-1793. XV Coloquio de Historia Canario-Americana. Las Palmas de Gran Canaria: Cabildo Insular de Gran Canaria, 2004, p. 894-911.

SANTANA PÉREZ, Germán; SANTANA PÉREZ, Juan Manuel. La puerta afortunada: Canarias en las relaciones hispano-africanas de los siglos XVII y XVIII. Madrid: La Catarata, 2002

SANTANA PÉREZ, Juan Manuel. Viera y Clavijo: historiador ilustrado del Atlántico. Historia da Historiografía (Ouro Preto). n.23, abr. 2017, p. 43-63.
SANTANA PÉREZ, Juan Manuel; SANTANA PÉREZ, Germán. La pesca en el banco sahariano, siglos XVII y XVIII. Madrid: La Catarata, 2014.

SILVEIRA, Luíz. Documentos portugueses sobre la acción de España en África (apontamentos acerca de fontes existentes em Portugal para o estudo da África espanhola). Madrid: Consejo Superior de Investigaciones Científicas, 1954. SOLBES FERRI, Sergio. Rentas reales y navíos de permisión a Indias. Las Palmas de Gran Canaria: Ministerio de Ciencia e Innovación; Universidad de Las Palmas de Gran Canaria, 2009.

SUÁREZ GRIMÓN, Vicente. Construcción naval y tráfico marítimo en Gran Canaria en la segunda mitad del siglo XVIII. IV Coloquio de Historia Canario-Americana (1980). Las Palmas de Gran Canaria: Cabildo Insular de Gran Canaria, 1982.

URTEAGA, Luis. La tierra esquilmada: las ideas sobre la conservación de la naturaleza en la cultura española del siglo XVIII. Madrid: Serbal/CSIC, 1987.

URTUSÁUSTEGUI, Juan Antonio de. Diario de viaje a la isla de El Hierro en 1779. Edición Manuel Lorenzo Perera. La Orotava: Centro de Estudios Africanos, 1983 [escrito en 1779].

VAN DEN BOOGAART, Ernst et al. La expansión holandesa en el Atlántico, 1580-1800. Madrid: Mapfre, 1992.

VASSALLO, Carmel. Corsairing to commerce: Maltese merchants in XVIII century Spain. Msida: University of Malta, 1997.

VIERA Y CLAVIJO, José de. Extracto de las actas de la Real Sociedad Económica de Amigos del País de Las Palmas (1777-1790). Las Palmas de Gran Canaria: Real Sociedad Económica de Amigos del País de Las Palmas, 1981[escrito en 1777-1790].

VIERA Y CLAVIJO, José de. Historia de Canarias, t. II. Santa Cruz de Tenerife: Goya, 1982 [escrito en 1763-1766].

VIERA Y CLAVIJO, José de. Historia natural de las Islas Canarias: indice alfabético descriptivo de sus tres reinos: animal, vegetal y mineral. La Laguna: Nivaria, 2005 [escrito en 1779]. 